\title{
Some properties of indium-tin oxide films
}

\author{
M C RADHAKRISHNA* and M RAMAKRISHNA RAO \\ Central Instruments and Services Laboratory, Indian Institute of Science, \\ Bangalore 560012 \\ *Present address: Sharpedge Ltd., Okhla Industrial Estate, New Delhi.
}

MS received 1 December 1976; revised 17 March 1977

\begin{abstract}
Thin films of indium-tin oxide have been deposited by DC diode sputtering from an indium-tin alloy target in an argon, hydrogen and oxygen atmosphere. Films with sheet resistance of $11 \mathrm{ohms} / \mathrm{square}$ and $80 \%$ light transmission have been obtained. The effect of cathode composition and gas mixture on sheet resistance and optical transmission properties of the films have been studied.
\end{abstract}

Keywords. Indium-tin oxide films; optical properties of thin films; reactive evaporation.

\section{Introduction}

Transparent conducting thin films have generally been obtained by vapour phase deposition of compound. In recent years, interest has been shown in thin films of indium oxide doped with tin (ITO) deposited by sputtering (Aitchson 1954, Vossen 1971, Rupprecht 1954, Muller 1968, Radhakrishna and Ramakrishna Rao 1973, Fraser and Cook 1972). These films have been deposited by R F Sputtering-both reactively and passively-from premixed targets which are in the form of either oxides or metals. The ITO films are of great interest in view of their characteristics like high light transmission (more than $80 \%$ in the visible region) low sheet resistance (less than 11 ohms per square) low temperature coefficient of resistance and high infrared reflectivity. These characteristics make indium-tin oxide films very useful for applications like optical device electrodes, transparent heating elements and infrared reflectors.

This paper reports our investigations on diode sputtered films of indium doped with tin in a reactive atmosphere. The influence of gas composition and target composition on sheet resistance and optical properties of the films have been reported.

\section{Sputtering procedure}

The indium oxide films were $\mathrm{DC}$ sputtered (diode-reactive) from a metal alloy target of tin and indium in $\mathrm{Ar}, \mathrm{H}_{2}$ and $\mathrm{O}_{2}$ gas mixture. The target composition was varied and the resistance measurements were made. The films with lowest resistance values were obtained from a cathode composition of indium with $5.6 \%$ tin by weight. The 
target was prepared by melting the alloy in a graphite crucible (high purity metals of 99.9\% were employed) in air. The outermost oxide layer was skimmed off before the alloy solidified. This alloy target was fixed to the water cooled cathode holder.

The sputtering vacuum system consisted of a $4^{\prime \prime}$ diffusion pump giving an ultimate vacuum of $1 \times 10^{-5}$ torr. The details of sputtering system has been described elsewhere (Radhakrishna and Ramakrishna Rao 1973).

The technique of sputtering was to evacuate the chamber to better than $1 \times 10^{-5}$ torr and then introducing argon, oxygen and hydrogen through three different needle valves to the required pressure. The constant pressure in the chamber is maintained by controlling gas input and throttling the high vacuum valve. The amount of gas bleeded was controlled by counting the number of bubbles of each gas passed through silicon oil. For all the experiments, except for the study of effect of gas composition, the gas composition of $50 \%$ argon, $25 \%$ oxygen and $25 \%$ hydrogen by volume was employed. This composition was arrived at after studying the effect of gas composition on the sheet resistance and optical transmission of the films. A gas pressure of 0.01 torr was maintained inside the bell jar throughout sputtering.

Glass slides of $25 \mathrm{~mm} \times 25 \mathrm{~mm}$ were used as substrates. These substrates were cleaned by the detergent teepol and rinsed in water. Finally 'breath figure test' was employed for checking the cleanliness of the substrates. The substrates were water cooled at ambient temperature during some trials and heated to $120^{\circ} \mathrm{C}$ during other trials.

After admitting the gas, and stabilising the pressure of the gas mixture at 0.01 torr, high voltage of 1000 volts was applied to the cathode and anode. Voltage was adjusted to get a current density of $3.0 \mathrm{~mA} / \mathrm{cm}^{2}$. Pre-sputtering was done with the shutter closed for about $5 \mathrm{~min}$ to activate the cathode.

Thickness of these films were measured by multiple beam interferometer and by transmission interference pattern. The error in thickness measurement was found to be $\pm 50 \AA$.

Electrical measurements were made by using four probe technique (Valdes 1954). Optical measurements were carried out using Unicam Spectrophotometer SP-700.

\section{Results}

The effect of gas composition (relative proportions of argon, oxygen and hydrogen) on the electrical and optical properties was studied. The experimental data for three different compositions are presented in table 1 and represented in figure 1.

The analysis of the data shown in table 1 indicates that the composition of $50 \% \mathrm{Ar}$, $25 \% \mathrm{O}_{2}$ and $25 \% \mathrm{H}_{2}$ by volume gives best results regarding the low electrical resistance and high transmission. The sputtering time is 40-45 min for the lowest sheet resistance, reported. The current density is $3 \mathrm{~mA} / \mathrm{cm}^{2}$. The other composition give either low sheet resistance with poor transmission or high transmission with high sheet resistance. The lower the oxygen content in the chamber, the greater the metallic nature of the film due to insufficient oxygen to form oxides. The addition of $\mathrm{H}_{2}$ enables the formation of hydride of metals which increases the conductivity of the films. The transmission curve shown in figure 4 gives neutral transmission in the visible region for the films made from a cathode of indium with $5.6 \%$ tin by weight, in an atmosphere of $50 \% \mathrm{Ar}, 25 \% \mathrm{O}_{2}$ and $25 \% \mathrm{H}_{2}^{-}$. The measurements were also carried out on substrates which were heated to $100^{\circ} \mathrm{C}$ before sputtering. At the 
Cathode composition INDIUM With $5.6 \%$ TIN by weight.

$\square-50 \% \mathrm{Ar}, 30 \% \mathrm{O}_{2}, 20 \% \mathrm{H}_{2}$

$x-75 \% \mathrm{Ar}, 10 \% \mathrm{O}_{2}, 15 \% \mathrm{H}_{2}$

$\longrightarrow 50 \% \mathrm{Ar}, 25 \% \mathrm{O}_{2}, 25 \% \mathrm{H}_{2}$

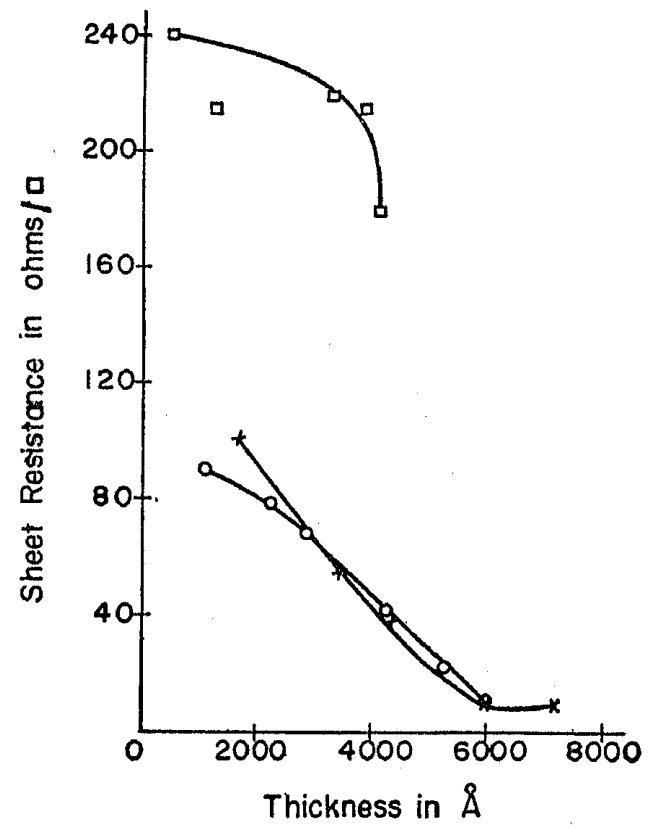

Figure 1. Variation of sheet resistance with thickness of the film at various gas compositions.

Table 1. Electrical and optical properties of indium-tin oxide films in argon, oxygen and hydrogen gas mixtures.

\begin{tabular}{cccc}
\hline $\begin{array}{c}\text { Gas composition } \\
\text { (by Vol.) }\end{array}$ & $\begin{array}{c}\text { Thickness } \\
\text { in } \AA\end{array}$ & $\begin{array}{c}\text { Resistance in } \\
\text { Ohm/Square }\end{array}$ & $\begin{array}{c}\mathrm{T} \% \\
\text { at } 5500 \AA\end{array}$ \\
\hline $50 \% \mathrm{Ar}, 30 \% \mathrm{O}_{2}, 20 \% \mathrm{H}_{2}$ & 500 & 240 & 90 \\
& 1251 & $215 \cdot 3$ & 84 \\
& 3250 & 220 & 80 \\
& 3846 & $215 \cdot 3$ & 80 \\
\hline $75 \% \mathrm{Ar}, 10 \% \mathrm{O}_{2}, 15 \% \mathrm{H}_{2}$ & 4110 & 180 & 78 \\
$\cdots$ & 1700 & 100 & 0 \\
& 3452 & 57 & 0 \\
& 4350 & 40 & 0 \\
$50 \% \mathrm{Ar}, 25 \% \mathrm{O}_{2}, 25 \% \mathrm{H}_{2}$ & 6000 & 9 & 0 \\
& 7200 & 9 & 0 \\
\hline
\end{tabular}




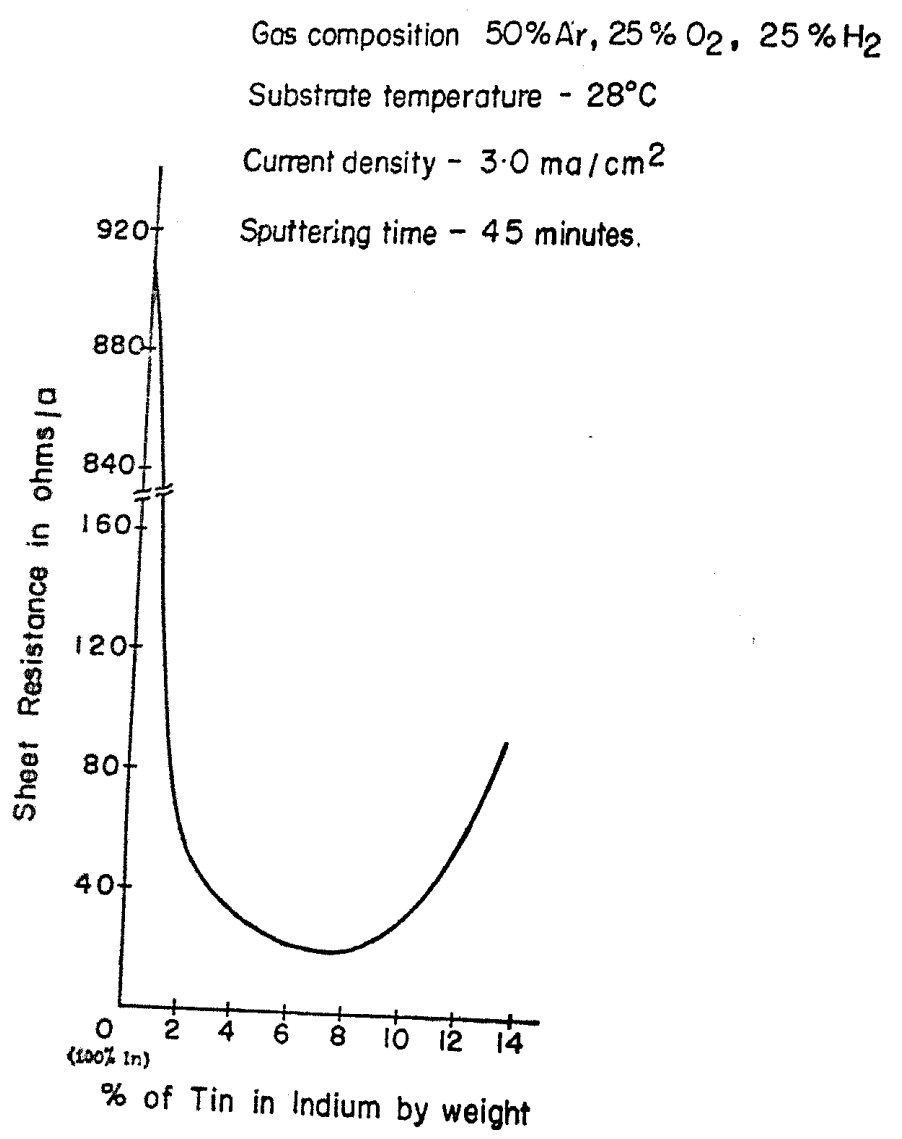

Figure 2. Thickness is sheet resistance of the film at different temperatures.

end of the sputtering the substrate recorded a temperature of $120^{\circ} \mathrm{C}$, and the resistance measurements were done at room temperature. The results are tabulated in table 3 substrate temperature at $120^{\circ} \mathrm{C}$ and $28^{\circ} \mathrm{C}$. values of sheet resistance of films with the temperature is to decrease the sheet resistan it is observed that the effect of increase in "tad values (Molzen 1975). It also confirms the which is in agreement with the reporcarrited out similar investigations on the films observations of Hecq (1974) who have $.00 \mathrm{C}$. The prolonged heating on the films deposited on the substrates at $40^{\circ} \mathrm{C}$ and denas in make the glass slide due to sputtering of the substrate and high current wed in this investigation. Hence higher substrate temperatures werent the wet resistance don. However, both the graphs follow the sames were not whet resistance decreases as the film thickness is increased.

Table 2. Sheet resistance of films with different

\begin{tabular}{cc}
\hline $\begin{array}{c}\text { Composition of cathode with tin \% } \\
\text { by weight }\end{array}$ & $\begin{array}{c}\text { Sheet resistance } \\
\text { Ohms/Square }\end{array}$ \\
\hline 0 & 906 \\
2 & 57 \\
5.6 & 23 \\
13.6 & 91 \\
\hline
\end{tabular}


The dependence of sheet resistance of the film on the chemical composition of the cathode was studied. Four cathodes having the composition of, pure indium ( $99.9 \%$ ), indium with $2 \%, 5.6 \%$ and $13.6 \%$ tin by weight were employed in this investigation. Figure 3 is the graphical representation of the sheet resistance versus cathode composition of the film. These films were analysed by mass spectrometer which gave the actual values of composition. They were sputtered in the gas mixture of $50 \% \mathrm{Ar}$, $25 \% \mathrm{O}_{2}$ and $25 \% \mathrm{H}_{2}$. The chemical composition of $5.6 \%$ tin by weight in indium has given the lowest resistance with an optical transmission of more than $80 \%$. Hecq et al (1974) reported that the best results were obtained for powder-mixture of $\mathrm{In}_{2} \mathrm{O}_{3}$ and $\mathrm{SnO}_{2}$ when indium and tin were in the ratio 9: 1 (atomic). The behaviour of the composition curve reported by us and Hecq et al is similar even though the starting materials are different.

\section{Stability of films}

These films are hard and can be cleaned with acids and alkalies. No reduction in

Gas composition $50 \% \mathrm{Ar}, 25 \% \mathrm{O}_{2}, 25 \% \mathrm{H}_{2}$

Cothode composition INDIUM with $5.6 \%$ TIN by weight.

Current density $3.0 \mathrm{ma} / \mathrm{cm}^{2}$

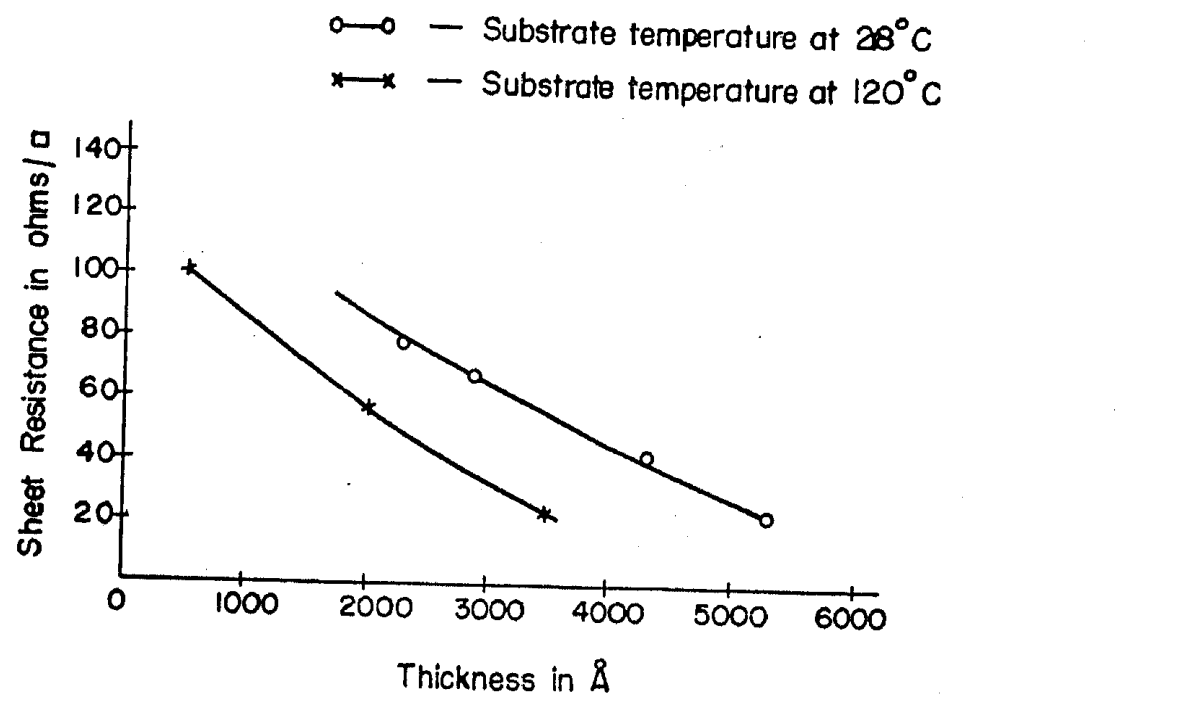

Figure 3. Percentage composition of tin in indium $v s$ sheet resistance.

Table 3. Resistance measurements recorded at $120^{\circ} \mathrm{C}$

\begin{tabular}{|c|c|c|}
\hline $\begin{array}{c}\text { Thickness } \\
\AA\end{array}$ & $\begin{array}{c}\text { Sheet resistance } \\
\text { Ohms/Square at } 120^{\circ} \mathrm{C}\end{array}$ & $\begin{array}{c}\text { Transmission } \\
\%\end{array}$ \\
\hline 510 & 100 & 80 \\
\hline 2012 & 56 & 80 \\
\hline 3500 & 23 . & 80 \\
\hline
\end{tabular}


Gas composition $50 \% \mathrm{Ar}, 25 \% \mathrm{O}_{2}, 25 \% \mathrm{H}_{2}$

Cathode composition INDIUM with $5.6 \%$ TIN by weight.

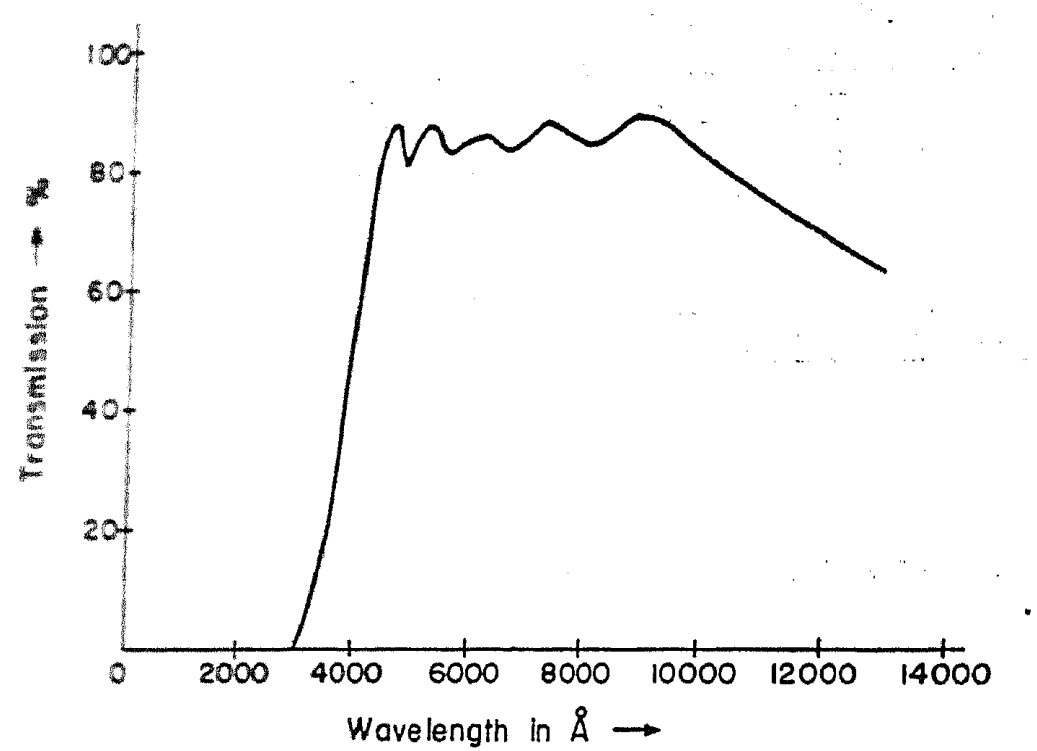

4hansmission curve of an indium oxide film. (Thickness of the film $=6000 \mathrm{~A}$ ).

(3) these films was found even after dipping for $30 \mathrm{~min}$ in strong acids and

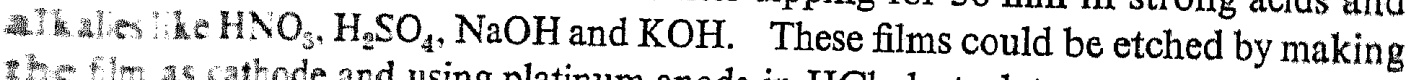
the $1 \mathrm{~m}$ asthode and using platinum anode in $\mathrm{HCl}$ electrolyte.

\section{Conchusion}

Inditum cride films of low sheet resistance of $11 \mathrm{ohms} / \mathrm{square}$ with transparancy of

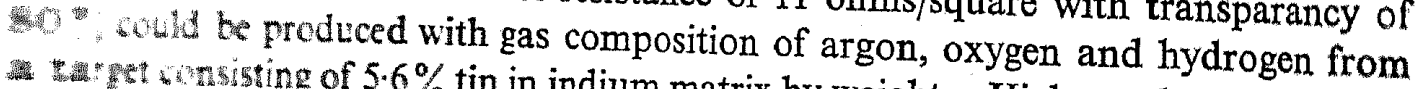

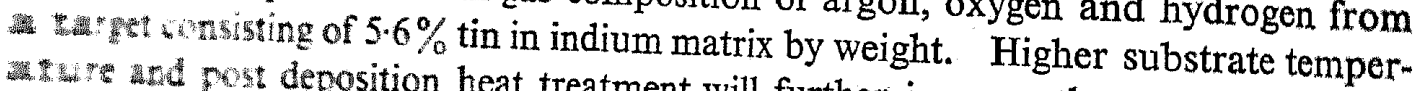
thetrot

\section{Achent}

W. whe our greateful thanks to Prof. S Dhawan, for his encouragement

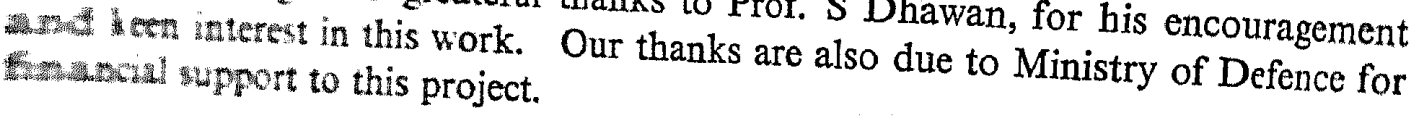

\section{2etertuces}

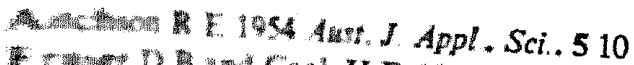

策.

In 51

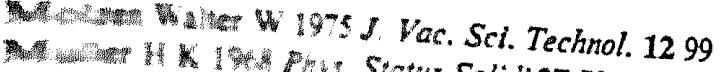

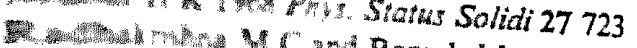

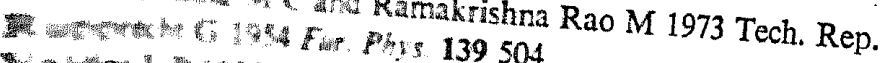

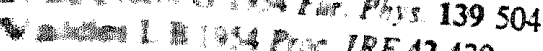

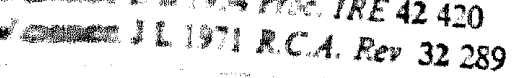

